\title{
Electrical characterization of electron irradiated and annealed lowly-doped $4 \mathrm{H}$-SiC
}

\author{
E. Omotoso ${ }^{1,2, *}$, A. T. Paradzah ${ }^{1}$, M. J. Legodi ${ }^{1}$, M. Diale ${ }^{1}$, W. E. Meyer ${ }^{1}$ and F. D. Auret ${ }^{1}$ \\ ${ }^{I}$ Department of Physics, University of Pretoria, Private Bag X20, Hatfield 0028, South Africa \\ ${ }^{2}$ Departments of Physics, Obafemi Awolowo University, Ile-Ife, 220005, Nigeria
}

${ }^{*}$ Corresponding author e-mail address: ezekiel.omotoso@up.ac.za

\begin{abstract}
The effect of high energy electron (HEE) irradiation on nickel Schottky contacts fabricated on lowly-doped $n$-type $4 H$-SiC was investigated by deep level transient spectroscopy (DLTS) and high resolution Laplace-DLTS. The Schottky contacts were deposited by resistive evaporation of nickel and were observed to be of good rectification quality from currentvoltage measurements. DLTS was performed up to $350 \mathrm{~K}$ to investigate the presence of defects before and after HEE irradiation. HEE irradiation was observed to induce three deep level defects below $350 \mathrm{~K}$ at $0.42 \mathrm{eV}, 0.62 \mathrm{eV}$ and $0.76 \mathrm{eV}$ below the conduction band minimum. These deep level defects are labelled $\mathrm{E}_{0.42}, \mathrm{E}_{0.62}$ and $\mathrm{E}_{0.76}$. Defects $\mathrm{E}_{0.42}$ and $\mathrm{E}_{0.76}$ were observed after the same electron fluence and were annealed out at the same temperature, suggesting that the defects could be strongly related. The effect of HEE irradiation and annealing on as-grown defects was also investigated and is reported.
\end{abstract}

Keywords: $4 H$-SiC, Schottky contacts, high energy electron irradiation, DLTS

\section{Introduction}

Silicon carbide is a wide bandgap semiconductor with desirable physical and electronic properties that makes it suitable for fabrication of high frequency, high temperature and high power devices [1-3]. SiC is also a radiation hard material making it a material of choice for devices that can operate in radiation harsh environments and at high temperatures [4]. Such devices include radiation detectors and devices for space applications. As with other 
semiconducting materials, use of a semiconductor in electronic device fabrication depends on the knowledge of presence of deep levels. This is specially so since defects can either enhance or degrade the devices. Thus, if the presence and effect of defects is well understood, controlled introduction into the material can be performed to enhance performance or the defects can be removed either by annealing or by other methods.

One way of controlled introduction of defects in semiconductors is by particle irradiation. This can be done by varying particle energy and fluence. Irradiation induces vacancies and interstitials in semiconductors, although many other complex defects can also result. Complex defects resulting from particle irradiation include Frenkel pairs, antisites (such as in compound semiconductors), vacancy pairs, etc. Particle irradiation is also used to shed light on the origin and in some instances on the microstructural nature of defects. In $\mathrm{SiC}$ for example, low energy particle irradiation can be used to differentiate between carbon and silicon related defects since these elements have a different threshold displacement energy. Irradiation with particles with low energy that is insufficient to produce silicon vacancies or related defects can thus only induce carbon vacancies and related defects.

Defects are described majorly using two parameters; the defect activation energy and the defect capture cross section. The defect activation energy, $E_{\mathrm{T}}$, refers to the position of the defect level with respect to either the conduction band or the valence band. The capture cross section, $\sigma_{n}$, relates to how effective the defect is in trapping free carriers. The defect concentration is also another parameter used to quantify a defect level.

To the best of our knowledge, the characterization of low doping density $\left(\sim 4 \times 10^{14} \mathrm{~cm}^{-3}\right) 4 H$ $\mathrm{SiC}$ after electron irradiation and thermal annealing has not been studied by high-resolution Laplace deep level transient spectroscopy (Laplace-DLTS). In this study, high energy electron (HEE) irradiation was performed using a strontium source on nitrogen doped $4 \mathrm{H}-\mathrm{SiC}$ with a doping density of $\sim 4 \times 10^{14} \mathrm{~cm}^{-3}$. Defects present in as-prepared as well as defects introduced 
by irradiation were characterized by conventional DLTS and Laplace-DLTS. Laplace-DLTS was used to separate defect levels with closely spaced emission rate. Annealing studies were also performed to study the annealing kinetics of the irradiation induced-defects as well as the as-prepared and process-induced defects.

\section{Experimental procedure}

The samples used in this work were epitaxially grown, $\mathrm{N}$-doped, $n$-type $4 H$-SiC wafers supplied by CREE Research Inc. The epilayer was grown by chemical vapour deposition on the Si-face of the SiC substrate, which has a low net doping density of $\sim 4.0 \times 10^{14} \mathrm{~cm}^{-3}$. The orientation and thickness of the samples are $8.05^{\circ}$ and 19.20 microns, respectively. Samples were degreased by boiling in trichloroethylene, acetone and methanol for 5 minutes each. This was followed by rinsing in de-ionised water before a 30 seconds dip in hydrofluoric acid to remove the native oxide layer. Samples were then rinsed in de-ionised water followed by blow drying using $\mathrm{N}_{2}$ gas. Nickel ohmic contact with a thickness of $300 \mathrm{~nm}$ was deposited by joule evaporation onto the highly doped $\left(1 \times 10^{18} \mathrm{~cm}^{-3}\right)$ side of the sample and annealed in flowing argon for 10 minutes at $950{ }^{\circ} \mathrm{C}$. Prior to Schottky contact fabrication, the same cleaning procedure was repeated except that instead of boiling, 3 minutes rinsing in each of the three solvents was performed in an ultrasonic bath. Nickel Schottky contacts with a diameter of $\sim 0.6 \mathrm{~mm}$ and a thickness of $100 \mathrm{~nm}$ were then resistively deposited onto the lowly doped side of the samples. DLTS measurements were carried out using a National Instruments Digital Acquisition (DAQ) based Laplace-DLTS system [5]. HEE irradiation of the diodes was performed using a Sr-90 radioactive source. Strontium decays with an emission of $\sim 0.55 \mathrm{MeV}$ into yttrium which then decays zirconium with an emission of $\sim 2.3$ $\mathrm{MeV}$. The electrons emitted from the strontium source thus have a continuous energy distribution, with more than $70 \%$ having more than $0.25 \mathrm{MeV}$. Detailed information on the irradiation source can be obtained from Auret et. al. [6]. The diodes were annealed after irradiation in steps of $100{ }^{\circ} \mathrm{C}$ in flowing argon gas up to $600{ }^{\circ} \mathrm{C}$. 


\section{Results and Discussion}

Current-voltage $(I-V)$ and capacitance-voltage $(C-V)$ measurements were carried out after Schottky contacts deposition to determine the rectification properties of the prepared Schottky contacts. The contacts had excellent rectification properties making it possible for DLTS measurements to be carried out on the samples. $I-V$ and $C-V$ measurements were also repeated after each irradiation step to determine if the diodes were still suitable for DLTS measurements. Parameters which were monitored from these measurements to determine the suitability of the diode for DLTS measurements include the ideality factor $(n)$, the Schottky barrier height obtained from both $I-V\left(\Phi_{\mathrm{I}-\mathrm{V}}\right)$ and $C-V\left(\Phi_{\mathrm{C}-\mathrm{V}}\right)$ and the reverse leakage current measured at $-5 \mathrm{~V}$. The ideality factor was obtained assuming the thermionic emission process to be the dominant current transport mechanism across the Schottky barrier. A summary of the obtained $I-V$ and $C-V$ measurements is presented in Table 1, as earlier reported in ref. [7]. A more detailed $I-V$ and $C-V$ study on characteristics of $4 \mathrm{H}-\mathrm{SiC}$ with $\mathrm{HEE}$ irradiation can be obtained from Omotoso et al. [8] It was demonstrated that $4 \mathrm{H}-\mathrm{SiC}$ retains its rectification properties after fluence of $6 \times 10^{14} \mathrm{~cm}^{-2}$ at room temperature [8].

Table 1. The diode ideality factor, Schottky barrier height and reverse leakage current obtained before irradiation, after irradiation and after annealing the irradiated diodes at $600{ }^{\circ} \mathrm{C}$.

\begin{tabular}{lcccc}
\hline Fluence & $n \pm 0.02$ & $\Phi_{\mathrm{I}-\mathrm{V}}(\mathrm{eV}) \pm 0.02$ & $\Phi_{\mathrm{C}-\mathrm{V}}(\mathrm{eV}) \pm 0.02$ & $I_{\mathrm{L}}(\mathrm{A})$ at $-5 \mathrm{~V}$ \\
\hline 0 & 1.05 & 1.62 & 2.13 & $1.2 \times 10^{-14}$ \\
$5.4 \times 10^{14} \mathrm{~cm}^{-2}$ & 1.04 & 1.60 & 2.14 & $5.2 \times 10^{-13}$ \\
$\begin{array}{l}5.4 \times 10^{14} \mathrm{~cm}^{-2}+600{ }^{\circ} \mathrm{C} \\
\text { annealing }\end{array}$ & 1.06 & 1.58 & 2.20 & $3.2 \times 10^{-12}$ \\
\hline
\end{tabular}

DLTS was carried out on the diodes before HEE irradiation, after HEE irradiation and during annealing of the irradiated diodes. A control measurement was done by annealing as-prepared diodes and taking DLTS measurements. Annealing the as-prepared diodes between $100{ }^{\circ} \mathrm{C}$ and $700{ }^{\circ} \mathrm{C}$ did not induce new defects. Any defect that may be observed during annealing of irradiated diodes is therefore as a result of irradiation and not annealing. 


\subsection{Irradiation results}

DLTS measurements were carried out in the temperature range $30 \mathrm{~K} \leq \mathrm{T} \leq 350 \mathrm{~K}$. The reverse bias was maintained as $5 \mathrm{~V}$ while a forward voltage pulse of $-1 \mathrm{~V}$ with a pulse width of $1 \mathrm{~ms}$ was applied. Normalized DLTS spectra obtained using a $2.5 \mathrm{~s}^{-1}$ rate window is given in Fig. 1 showing the presence of four defect levels. The energy levels were labelled $\mathrm{E}_{0.10}$, $\mathrm{E}_{0.12}, \mathrm{E}_{0.18}$ and $\mathrm{E}_{0.69}$ with activation energies of $E_{\mathrm{C}}-0.10 \mathrm{eV}, E_{\mathrm{C}}-0.12 \mathrm{eV}, E_{\mathrm{C}}-0.18 \mathrm{eV}$ and $E_{\mathrm{C}}-0.69 \mathrm{eV}$. The level $\mathrm{E}_{0.10}$ is a shallow nitrogen donor occupying a cubic lattice site $[9,10]$. When occupying a hexagonal site, nitrogen dopants introduce shallow energy levels with an activation energy of $\sim 0.055 \mathrm{eV}[11,12]$.

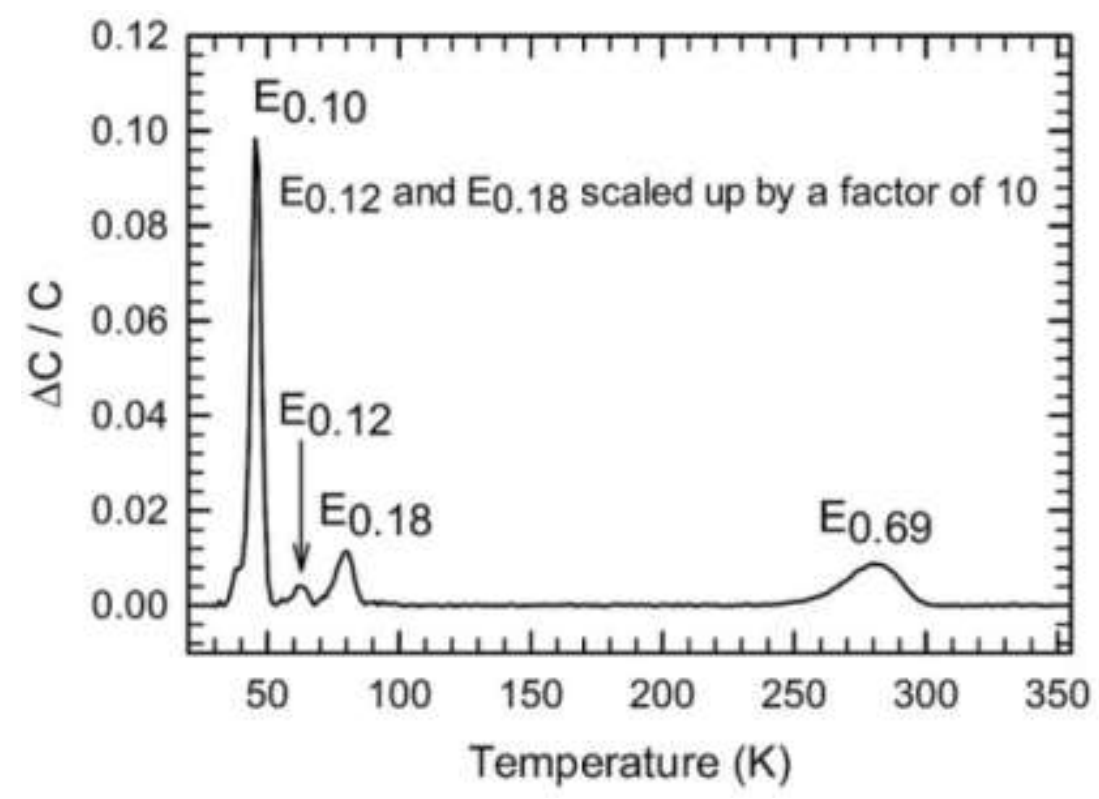

Fig. 1. DLTS spectra for the as-deposited sample. Spectra recorded at $5 \mathrm{~V}$, and rate window of $2.5 \mathrm{~s}^{-1}$.

Energy level $\mathrm{E}_{0.12}$ was observed and has been attributed to a titanium impurity $[13,14] . \mathrm{E}_{0.18}$ has also been attributed to a titanium impurity $[14,15]$. It is possible that these two defect levels are both induced by a titanium impurity but occupying different geometrical positions in $\mathrm{SiC}$. The defect is seen as $\mathrm{E}_{0.12}$ when occupying a hexagonal position while it appears as $\mathrm{E}_{0.18}$ when occupying a cubic position. A comprehensive study of the two defect levels is provided by Achtziger et al. after implanting $4 \mathrm{H}-\mathrm{SiC}$ with radioactive isotopes of chromium 
and vanadium [14]. The authors who also observe defect level $\mathrm{E}_{0.18}$ however attribute it to a chromium impurity in contrast to Castaldini et al [15]. Metal impurities in as-grown semiconductors are introduced during growth of the semiconductors.

Defect level $\mathrm{E}_{0.69}$ observed in this study is widely believed to be of intrinsic nature. From the literature, this defect has been attributed to a carbon vacancy, $\mathrm{V}_{\mathrm{C}}$ [16], a silicon vacancy [17], a silicon-carbon divacancy, $\mathrm{V}_{\mathrm{Si}}+\mathrm{V}_{\mathrm{C}}$, a carbon silicon antisite pair, $\mathrm{Si}_{\mathrm{C}}+\mathrm{C}_{\mathrm{Si}}$ [18]. It has also been claimed that the defect could be a silicon antisite-silicon vacancy complex, $\mathrm{C}_{\mathrm{Si}}-\mathrm{V}_{\mathrm{Si}}$ [18] and a nitrogen impurity next to a carbon interstitial $\mathrm{I}_{\mathrm{C}}+\mathrm{N}$ [19]. The problem of whether the defect level is either a silicon or carbon related defect was resolved by Son et al., and has been identified as double acceptor of an isolated carbon vacancy [20].

The normalized DLTS spectra obtained in this study after HEE irradiation are shown in Fig. 2. The presented spectra were obtained using a reverse bias of $5 \mathrm{~V}$, a forward pulse of $-1 \mathrm{~V}$ with a pulse width of $1 \mathrm{~ms}$ at a $2.5 \mathrm{~s}^{-1}$ rate window. The signatures (activation energy and apparent capture cross section) of the deep level defects show in Fig. 3 were determined as reported earlier [21].

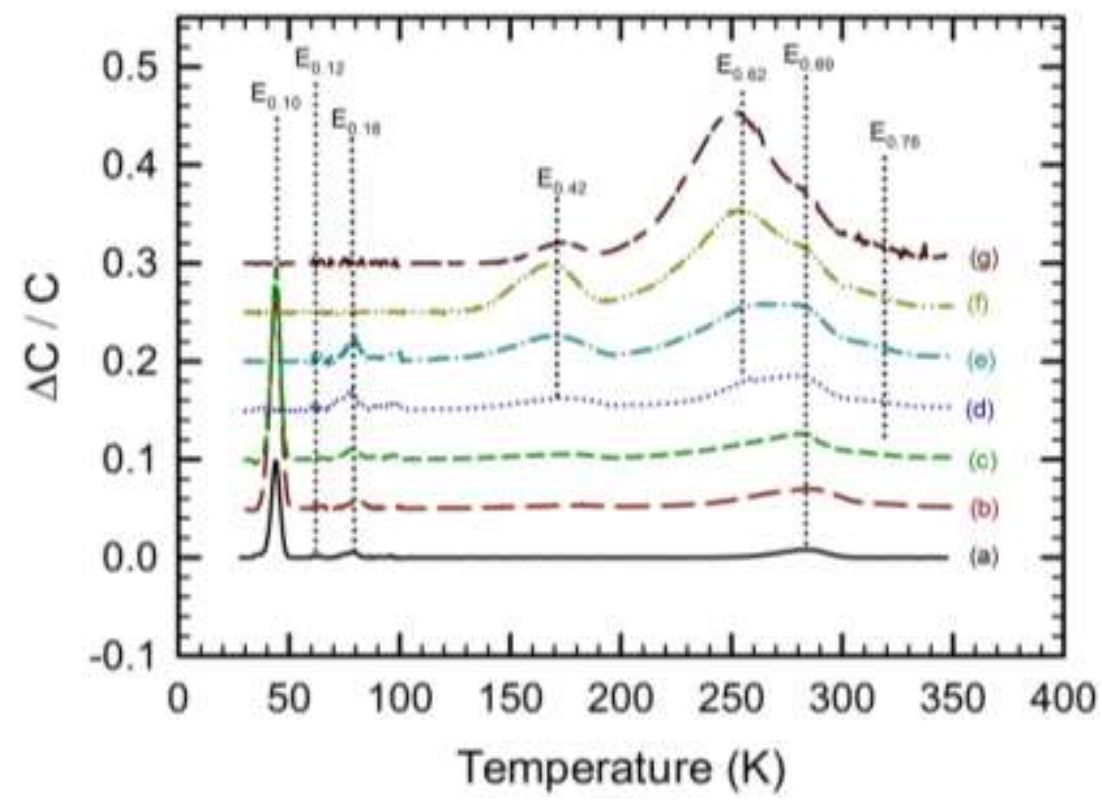

Fig. 2. Spectra produced at different electron fluence irradiations. (a) as-prepared, (b) $9.8 \times 10^{13} \mathrm{~cm}^{-2}$, (c) $2.0 \times$ $10^{14} \mathrm{~cm}^{-2}$ (d) $2.9 \times 10^{14} \mathrm{~cm}^{-2}$, (e) $3.9 \times 10^{14} \mathrm{~cm}^{-2}$, (f) $4.9 \times 10^{14} \mathrm{~cm}^{-2}$ (g) $5.4 \times 10^{14} \mathrm{~cm}^{-2}$. 


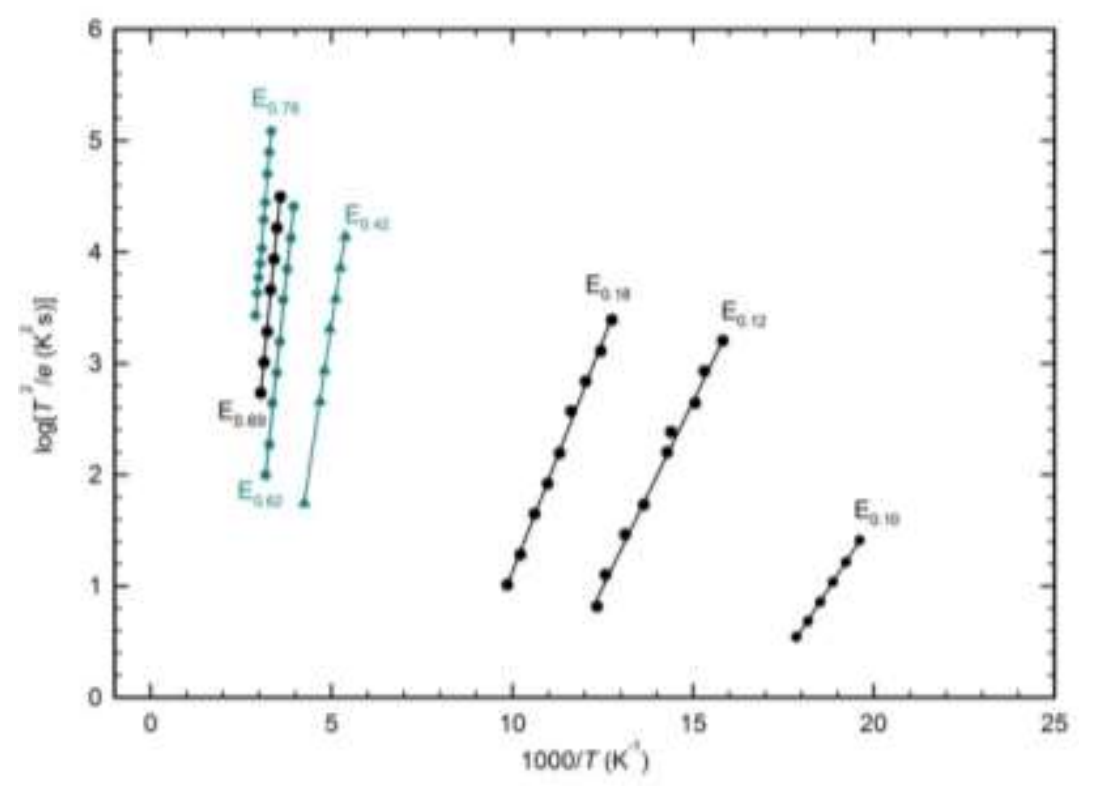

Fig. 3. Arrhenius plots of the defects obtained before and after HEE irradiation.

Using step by step high energy electron irradiation, defect level $\mathrm{E}_{0.69}$ was observed to increase in concentration from $2 \times 10^{13} \mathrm{~cm}^{-3}$ before irradiation to $9 \times 10^{13} \mathrm{~cm}^{-3}$ after a total fluence of $5.4 \times 10^{14} \mathrm{~cm}^{-2}$. Apart from level $\mathrm{E}_{0.69}$, another defect level with activation energy of $E_{\mathrm{C}}-$ $0.62 \mathrm{eV}$ was observed as the fluence increased. After an electron fluence of $4.9 \times 10^{14} \mathrm{~cm}^{-2}$, the concentration of level $\mathrm{E}_{0.62}$ had surpassed that of level $\mathrm{E}_{0.69}$, and the level $\mathrm{E}_{0.69}$ was only appearing as a shoulder of $\mathrm{E}_{0.62}$. The two broad defect levels obtained by conventional DLTS were separated more accurately into three distinct defect level by high resolution LaplaceDLTS as shown in Fig. 4. We have also observed the defect level $\mathrm{E}_{0.62}$ after 5.4 MeV alphaparticle irradiation on $4 \mathrm{H}-\mathrm{SiC}[22,23]$. In general, it may be deduced that different types of irradiation induced the same type of defects although in different concentrations depending on the energies of the irradiation particles as well as their masses. 


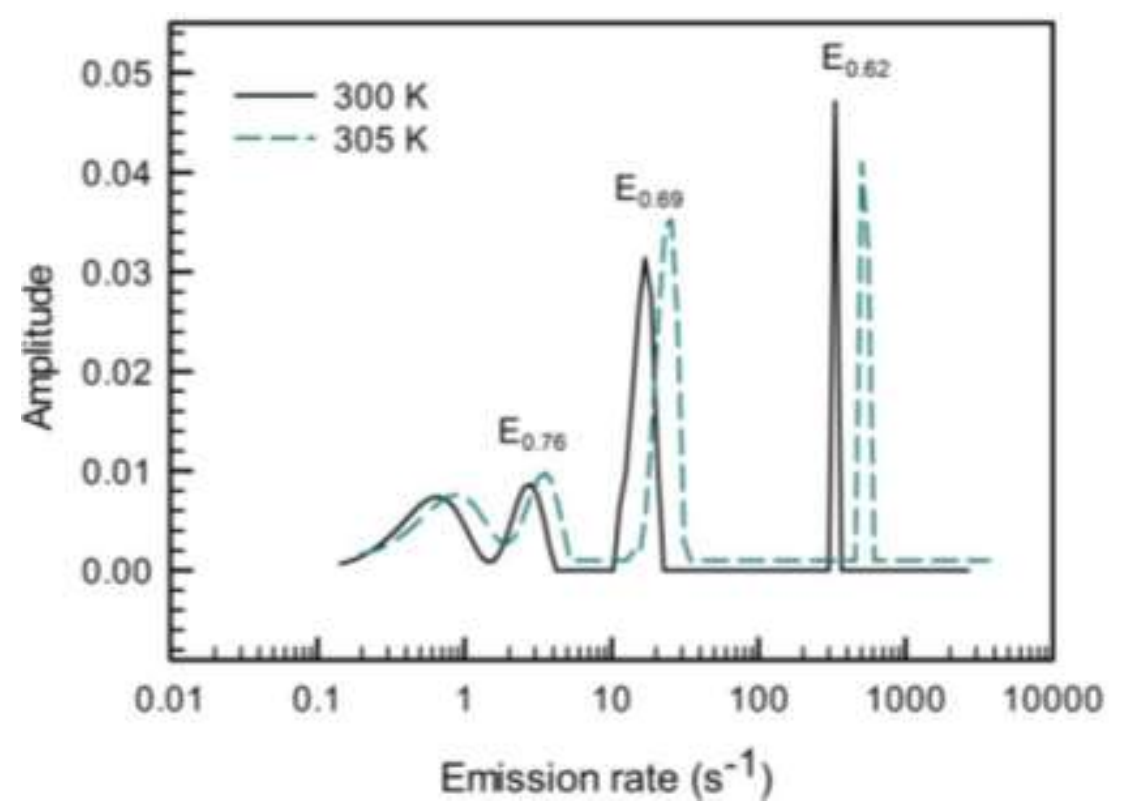

Fig. 4. Laplace-DLTS spectra showing emission rates of levels $E_{0.62}, E_{0.69}$ and $E_{0.76}$. The fourth peak was determined to be a measurement artefact.

Defect level $\mathrm{E}_{0.69}$ is commonly referred to as the $\mathrm{Z}_{1} / \mathrm{Z}_{2}$ defect. This level is believed to be a defect complex consisting of two closely spaced levels $\mathrm{Z}_{1}$ and $\mathrm{Z}_{2}$ that have negative $\mathrm{U}$ behaviour [24]. After $5.4 \mathrm{MeV}$ alpha particle irradiation of 4H-SiC, Ashgar et al. [25] proposed the defect exist as a single level but is transformed into a complex by irradiation. This attribute to an introduction of another level, $Z_{2}$ which is a carbon vacancy and is superimposed on $Z_{1}$. In this study, the irradiation electrons had enough energy to displace carbon from its lattice position hence the attribution of the $\mathrm{E}_{0.62}$ level to a carbon vacancy is supported. This does not however rule out the possible participation of carbon in the structure of the defect since the electron energy is enough to create carbon related defects. The displacement energy for carbon in a $\mathrm{SiC}$ lattice is approximately $19 \mathrm{eV}$ for the carbon sublattice and $38 \mathrm{eV}$ for the silicon sublattice [26].

After a total fluence of $1.5 \times 10^{14} \mathrm{~cm}^{-2}$, a defect level with energy $E_{\mathrm{C}}-0.42 \mathrm{eV}$ was observed with a low concentration of $3.8 \times 10^{12} \mathrm{~cm}^{-3}$. The concentration of the defect increased to 6.2 $\times 10^{13} \mathrm{~cm}^{-3}$ after a $5.4 \times 10^{14} \mathrm{~cm}^{-3}$ fluence. This defect shows acceptor like properties $[27,28]$ and has been attributed to a silicon vacancy [29]. In addition to $\mathrm{E}_{0.42}$ and $\mathrm{E}_{0.62}$, another deep 
level is introduced by high energy electron irradiation at $E_{\mathrm{C}}-0.76 \mathrm{eV}$, with a capture cross section of $1.0 \times 10^{-14} \mathrm{~cm}^{2}$. This defect appeared as a shoulder of $\mathrm{E}_{0.69}$ on the high temperature side. The structure of this defect has not been reported in literature despite its presence having been reported after alpha-particle, electron and proton irradiation [27, 30, 31]. However, since this defect is introduced by irradiation, it is possibly generally related to carbon vacancies, silicon vacancies, carbon or silicon interstitials, carbon or silicon antisites or complexes of these possibilities.

The defect energy levels $\left(E_{\mathrm{T}}\right)$, apparent capture cross sections $\left(\sigma_{\text {app }}\right)$ and the defect concentrations $\left(N_{\mathrm{T}}\right)$ determined for each defect are summarized in Table 2.

Table 2. Activation energy $E_{\mathrm{T}}$, apparent capture cross section $\sigma_{\text {app }}$ and concentration $N_{\mathrm{T}}$ of the observed defects.

\begin{tabular}{lccc}
\hline Defect label & $E_{\mathrm{T}}(\mathrm{eV})$ & $\sigma_{\text {app }}\left(\mathrm{cm}^{2}\right)$ & $N_{\mathrm{T}}\left(\mathrm{cm}^{-3}\right)$ \\
\hline $\mathrm{E}_{0.10}$ & $0.10 \pm 0.01$ & $1 \times 10^{-13}$ & $9.1 \times 10^{13}$ \\
$\mathrm{E}_{0.12}$ & $0.12 \pm 0.01$ & $7 \times 10^{-15}$ & $2.2 \times 10^{11}$ \\
$\mathrm{E}_{0.18}$ & $0.18 \pm 0.01$ & $6 \times 10^{-15}$ & $5.4 \times 10^{11}$ \\
$\mathrm{E}_{0.42}$ & $0.42 \pm 0.03$ & $8 \times 10^{-15}$ & $* 6.2 \times 10^{13}$ \\
$\mathrm{E}_{0.62}$ & $0.62 \pm 0.02$ & $2 \times 10^{-14}$ & $?$ \\
$\mathrm{E}_{0.69}$ & $0.69 \pm 0.02$ & $8 \times 10^{-15}$ & $* 9.3 \times 10^{13}$ \\
$\mathrm{E}_{0.76}$ & $0.76 \pm 0.03$ & $1 \times 10^{-14}$ & $* 4.9 \times 10^{13}$ \\
\hline
\end{tabular}

* Defect concentration obtained after electron fluence of up to $5.4 \times 10^{14} \mathrm{~cm}^{-2}$

\subsection{Annealing results}

After irradiation to a total fluence of $5.4 \times 10^{14} \mathrm{~cm}^{-2}$, the diodes were isochronally annealed in steps of $100{ }^{\circ} \mathrm{C}$ in flowing argon to a maximum temperature of $600{ }^{\circ} \mathrm{C}$. The annealing was done at each temperature for 15 minutes and DLTS measurements were repeated after each annealing. The normalized DLTS spectra obtained are shown in Fig. 5. There was no noticeable effect observed after annealing the irradiated samples at $100{ }^{\circ} \mathrm{C}$. 


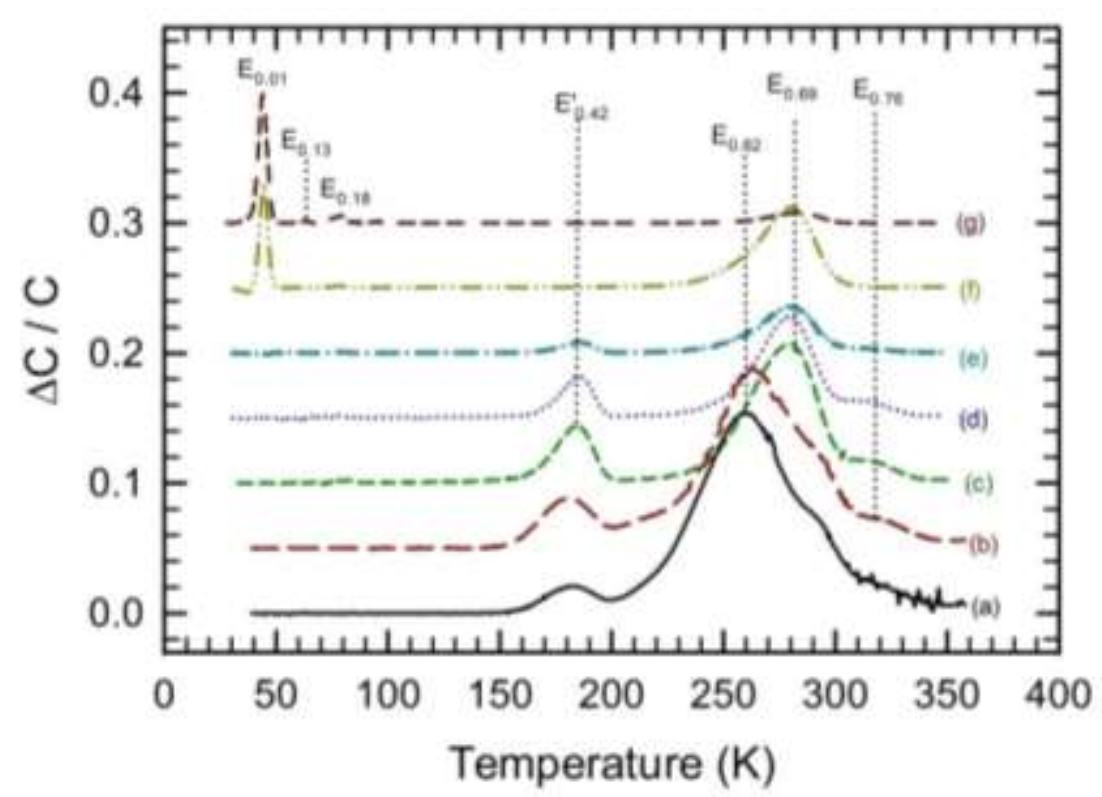

Fig. 5. DLTS spectra obtained after different annealing steps. The spectra obtained before and after irradiation at $5.4 \times 10^{14} \mathrm{~cm}^{-2}$ are also shown for comparison. (a) after irradiation, (b) $100{ }^{\circ} \mathrm{C}$, (c) 200 ${ }^{\circ} \mathrm{C}$, (d) $300{ }^{\circ} \mathrm{C}$, (e) $400{ }^{\circ} \mathrm{C}$, (f) $500{ }^{\circ} \mathrm{C}$ and (g) as prepared. The $500{ }^{\circ} \mathrm{C}$ and $600{ }^{\circ} \mathrm{C}$ spectra were similar hence, the $600{ }^{\circ} \mathrm{C}$ spectrum is not shown.

The first annealing induced difference was observed at $200{ }^{\circ} \mathrm{C}$ on defect level $\mathrm{E}_{0.62}$. The defect was completely annealed out after a 15 minutes heat treatment. The low temperature annealing out of the defect shows that the defect is highly unstable. During the annealing process, the concentration of defect $\mathrm{E}_{0.69}$ was observed to decrease systematically. However, after annealing at $600{ }^{\circ} \mathrm{C}$, the concentration of the defect remained above the pre-irradiation concentration levels.

The concentration of both $\mathrm{E}_{0.42}$ and $\mathrm{E}_{0.76}$ were reduced by annealing. After annealing at 500 ${ }^{\circ} \mathrm{C}$, both defects were annealed beyond detection levels. Similar annealing dynamics of these defects suggest that either the two defects require the same annealing sink or they act as an annealing sink to the same type of mobile defects [17]. The effect of annealing on levels $\mathrm{E}_{0.12}$ and $\mathrm{E}_{0.18}$ was not noticeable due to the low concentration of the defects while level $\mathrm{E}_{0.10}$ which had been completely suppressed by irradiation showed recovery after annealing at 
$500{ }^{\circ} \mathrm{C}$. The reason why irradiation suppresses this level with a reversal from annealing has been reported earlier by Omotoso et al. [31].

\section{Conclusions}

High-resolution Laplace DLTS has been successfully used to separate two broad defects (E0.62 and E0.69) obtained by conventional DLTS into three distinct defects.

The high energy electron irradiation up to fluence of $5.4 \times 10^{14} \mathrm{~cm}^{-2}$ introduced three defect levels $\mathrm{E}_{0.42}, \mathrm{E}_{0.62}$ and $\mathrm{E}_{0.76}$. Laplace DLTS was used to resolve defect level $\mathrm{E}_{0.76}$ which partially overlaps with defect $\mathrm{E}_{0.69}$, to give the activation energy with more accuracy. The level $\mathrm{E}_{0.62}$ was annealed out after annealing at a temperature of $200{ }^{\circ} \mathrm{C}$. Levels $\mathrm{E}_{0.42}$ and $\mathrm{E}_{0.76}$ were relatively stable up to annealing temperatures of $400{ }^{\circ} \mathrm{C}$ although the concentrations were reduced progressively. After annealing at $500{ }^{\circ} \mathrm{C}$, these levels were completely annealed out. These two defects are proposed to be closely linked in structure due to similar introduction and annealing dynamics. Level $\mathrm{E}_{0.10}$ which is a nitrogen impurity was completely suppressed by irradiation but was recovered after annealing at $500{ }^{\circ} \mathrm{C}$.

\section{Acknowledgements}

The authors would like to acknowledge the financial support of the University of Pretoria. The Postdoctoral Fellowship Program of the University of Pretoria funded Ezekiel Omotoso. This work is based on research supported by the National Research Foundation (NRF) of South Africa. The Grant-holders acknowledge that opinions expressed, findings and conclusions arrived at, are those of the authors and are not necessarily to be attributed to the NRF.

\section{References}

[1] L.M. Tolbert, B. Ozpineci, S.K. Islam, M.S. Chinthavali, Wide bandgap semiconductors for utility applications, Power and Energy Systems, Proceedings 1 (2003) 317-321.

[2] V. Kazukauskas, J.-V. Vaitkus, Influence of defect traps and inhomogeneities of SiC crystals and radiation detectors on carrier transport, Opto-Electronic Review 12(4) (2004) 377-382.

[3] J. Grant, W. Cunningham, A. Blue, V. O’Shea, J. Vaitkus, E. Gaubas, M. Rahman, Wide bandgap semiconductor detectors for harsh radiation environments, Nuclear Instruments and Methods in Physics 
Research Section A: Accelerators, Spectrometers, Detectors and Associated Equipment 546(1-2) (2005) 213217.

[4] M. Rogalla, K. Runge, A. Soldner-Rembold Particle detectors based on semi-insulating silicon carbide, Nuclear Physics B - Proceedings Supplements 78 (1999) 516.

[5] L. Dobaczewski, P. Kaczor, I. Hawkins, A. Peaker, Laplace transform deep-level transient spectroscopic studies of defects in semiconductors, Journal of applied physics 76(1) (1994) 194-198.

[6] F. Auret, S. Goodman, G. Myburg, W. Meyer, Electrical characterization of defects introduced in n-GaAs by alpha and beta irradiation from radionuclides, Appl. Phys. A 56(6) (1993) 547-553.

[7] A. Paradzah, E. Omotoso, M. Legodi, F. Auret, W. Meyer, M. Diale, Electrical Characterization of High Energy Electron Irradiated Ni/4H-SiC Schottky Barrier Diodes, Journal of Electronic Materials (2016) 1-6.

[8] E. Omotoso, W. Meyer, F. Auret, A. Paradzah, M. Diale, S. Coelho, P.J. van Rensburg, The influence of high energy electron irradiation on the Schottky barrier height and the Richardson constant of Ni/4H-SiC Schottky diodes, Materials Science in Semiconductor Processing 39 (2015) 112-118.

[9] T. Kimoto, A. Itoh, H. Matsunami, S. Sridhara, L. L. Clemen, R. P. Devaty, W.J. Choyke, T. Dalibor, C. Peppermu“ ller, G. Pensl, Nitrogen donors and deep levels in high-quality 4H-SiC epilayers grown by chemical vapor deposition, Applied Physics Letters 67(19) (1995) 2833.

[10] A. Castaldinia, A. Cavallinia, L. Polentaa, F.Navab, C. Canalic, C. Lanzierid, Deep levels in silicon carbide Schottky diodes, Applied Surface Science 187(3-4) (2002) 248.

[11] C.Q. Chen, J. Zeman, F. Engelbrecht, C. Peppermüller, R. Helbig, Z.H. Chen, G. Martinez, Photothermal ionization spectroscopy of shallow nitrogen donor states in 4H-SiC, Journal of Applied Physics 87(8) (2000) 3800 .

[12] A.O. Evwaraye, S.R. Smith, W.C. Mitchel, Electrical and Optical Properties of Defects in N-Type 4h-SiC, MRS Online Proceedings Library 410 (1995).

[13] N. Achtziger, W. Witthuhn, Band gap states of Ti, V, and Cr in 4H-silicon carbide, Applied Physics Letters 71 (1) (1997) 110.

[14] N. Achtziger, W. Witthuhn, Band-gap states of Ti, V, and $\mathrm{Cr}$ in 4H-SiC: Identification and characterization by elemental transmutation of radioactive isotopes, Physical Review B 57(19) (1998) 12181-12196.

[15] A. Castaldini, A. Cavallini, L. Rigutti, F. Nava, S. Ferrero, F. Giorgis, Deep levels by proton and electron irradiation in 4H-SiC, Journal of Applied Physics 98(5) (2005) 053706.

[16] T. Hiyoshi, T. Kimoto, Elimination of the Major Deep Levels in n- and p-Type 4H-SiC by Two-Step Thermal Treatment, Applied Physics Express 2(9) (2009) 091101.

[17] L. Storasta, J.P. Bergman, E. Janzén, A. Henry, J. Lu, Deep levels created by low energy electron irradiation in 4H-SiC, Journal of Applied Physics 96(9) (2004) 4909-4915.

[18] J. Zhang, L. Storasta, J. P. Bergman, N. T. Son, E. Janzén, Electrically active defects in n-type 4H-silicon carbide grown in a vertical hot-wall reactor, Journal of Applied Physics 93(8) (2003) 4708.

[19] I. Pintilie, L. Pintilie, K. Irmscher, B. Thomas, Formation of the Z1,2 deep-level defects in 4H-SiC epitaxial layers: Evidence for nitrogen participation, Applied Physics Letters 81(25) (2002) 4841-4843.

[20] N.T. Son, X.T. Trinh, L.S. Løvlie, B.G. Svensson, K. Kawahara, J. Suda, T. Kimoto, T. Umeda, J. Isoya, T. Makino, T. Ohshima, E. Janzén, Negative-\$U\$ System of Carbon Vacancy in \$4H-SiC, Physical Review Letters 109(18) (2012) 187603.

[21] F.D. Auret, P.N.K. Deenapanray, Deep Level Transient Spectroscopy of Defects in High-Energy LightParticle Irradiated Si, Critical Reviews in Solid State and Materials Sciences 29(1) (2004) 1-44.

[22] A. Paradzah, F. Auret, M. Legodi, E. Omotoso, M. Diale, Electrical characterization of $5.4 \mathrm{MeV}$ alphaparticle irradiated 4H-SiC with low doping density, Nuclear Instruments and Methods in Physics Research Section B: Beam Interactions with Materials and Atoms 358 (2015) 112-116.

[23] E. Omotoso, W.E. Meyer, F.D. Auret, A.T. Paradzah, M. Diale, S.M.M. Coelho, P.J. Janse van Rensburg, P.N.M. Ngoepe, Effects of $5.4 \mathrm{MeV}$ alpha-particle irradiation on the electrical properties of nickel Schottky diodes on 4H-SiC, Nuclear Instruments and Methods in Physics Research Section B: Beam Interactions with Materials and Atoms 365, Part A (2015) 264-268.

[24] C.G. Hemmingsson, N.T. Son, A. Ellison, J. Zhang, E. Janzen, Negative-U centers in 4H silicon carbide, Physical Review B 58(16) (1998).

[25] M. Asghar, I. Hussain, H.S. Noor, F. Iqbal, Q. Wahab, A.S. Bhatti, Properties of dominant electron trap center in n-type SiC epilayers by means of deep level transient spectroscopy, Journal of Applied Physics 101(7) (2007) 073706.

[26] G. Lucas, L. Pizzagalli, Ab initio molecular dynamics calculations of threshold displacement energies in silicon carbide, PHYSICAL REVIEW B 72(16) (2005) 161202.

[27] J. P. Doyle, M. K. Linnarsson, P. Pellegrino, N. Keskitalo, B.G. Svensson, A. Scho“ner, N. Nordell, J.L. Lindstro“m, Electrically active point defects in n-type 4H-SiC, Journal of Applied Physics 84(3) (1998) 1354. [28] T.A.G. Eberlein, R. Jones, P.R. Briddon, Z1/Z2 Defects in 4H-SiC, Physical Review Letters 90(22) (2003) 225502.

[29] F. Nava, G. Bertuccio, A. Cavallini, E. Vittone, Silicon carbide and its use as a radiation detector material, Measurement Science and Technology 19(10) (2008) 102001. 
[30] A. Castaldini, A. Cavallini, L. Rigutti, F. Nava, Low temperature annealing of electron irradiation induced defects in 4H-SiC, Applied Physics Letters 85(17) (2004) 3780.

[31] E. Omotoso, W.E. Meyer, F.D. Auret, A.T. Paradzah, M.J. Legodi, Electrical characterization of deep levels created by bombarding nitrogen-doped $4 \mathrm{H}-\mathrm{SiC}$ with alpha-particle irradiation, Nuclear Instruments and Methods in Physics Research Section B: Beam Interactions with Materials and Atoms 371 (2016) 312-316. 